\title{
ESCORE DA CONTAGEM DE CÉLULAS SOMÁTICAS E SUAS RELAÇÕES COM A CONTAGEM BACTERIANA TOTAL EM AMOSTRAS DE LEITE DE TANQUE NO ESTADO DO PARANÁ, BRASIL
}

(Somatic cell score and its relations with bacterial total count in bulk tank milk samples in the state of Paraná, Brazil)

Newton Pohl Ribas, Altair Antonio Valotto, José Algusto Horst, Uriel Vinicius Cotarelli de Andrade, Hendyel Aparecida Pacheco, Andressa Regonato ${ }^{1}$

1 Correspondência: newtonribas.ufpr@gmail.com

RESUMO: Avaliou-se os efeitos de meio com destaque para escore da contagem de células somáticas (ECS) sobre a contagem bacteriana total (CBT) e logarítmico da contagem bacteriana total (logCBT) de 685.032 amostras refrigeradas de leite de tanques individuais, comunitários e latões, coletadas pelas indústrias de laticínios em propriedades localizadas em dez regiões no Estado do Paraná, analisadas no período de janeiro de 2012 a maio de 2014. As médias estimadas, desvios-padrão e coeficientes de variação foram: CBT (1.307.000 \pm 1.859 .000 (UFC/mL), 136,7\%); $\log$ CBT $(5,89 \pm 1,93$ (log10UFCxmL-1), 29,5\%); CCS (568 \pm 575 (x1.000 células $/ \mathrm{mL}) 96,10 \%)$; ECS $(4,95 \pm 1,36,30,06 \%)$ e idade da amostra $(2,95 \pm 1,48$ dias), respectivamente. O Escore da Contagem de Células Somáticas (ECS) influenciou significativamente $(\mathrm{P}<0,01)$ a CBT e o logCBT. Os coeficientes de correlação de Pearson obtidos entre a CBT, logCBT e o ECS, foram de magnitude média e positivos de 0,155 ( $\mathrm{P}<0,001)$ e $0,267(\mathrm{P}<0,001)$, respectivamente. Os resultados evidenciam a necessidade pelos produtores, técnicos e indústrias de reavaliarem a gestão dos programas de controle da mastite que focam a saúde da glândula mamária, procedimentos de higiene dos equipamentos de ordenha, resfriamento, temperatura e tempo de armazenagem do leite, melhorando a qualidade microbiológica do leite e implantação de programas de pagamento por qualidade baseados na CCS e CBT.

Palavras-chave: contagem de células somáticas; correlações; estudo de frequências; qualidade microbiológica do leite

ABSTRACT: Were evaluated the effects of environment especially for Somatic Cell Count Scores (SCCS) on the Total Bacterial Count (TBC) and the Logarithmic Total Bacterial Count (logTBC) of 685,032 refrigerated milk samples of individual tanks, communal and cans, collected by dairy industries in properties located in ten regions in the state of Paraná, analyzed from January 2012 to May 2014. The estimated averages, standard deviation and coefficient of variation were: TBC $( \pm 1.307$ million 1.859 million (CFU / mL), 136.7\%); logTBC (5.89 \pm 1.93 (log10 CFUxmL-1), 29.5\%); SCC (568 \pm 575 (x1000 cells / ml) 96,10\%); SCS (4.95 $\pm 1.36,30.06 \%)$ and age of the sample (2.95 \pm 1.48 days), respectively. The Somatic Cell Count Scores (SCCS) influenced significantly $(P<0.01)$ the TBC and the logTBC. Pearson correlation coefficients between TBC, logTBC and SCCS were positive magnitude and average $0.155(P<0.001)$ and $0.267(P<0.001)$, respectively. The results shows the need of producers, technicians and industry reassess the management of mastitis control programs that focus on the health of the mammary gland, hygiene procedures of milking equipment, cooling, temperature and milk storage time, improving microbiological quality of milk and by payment programs based on SCC and TBC.

Key Words: correlations; microbiological quality of milk; somatic cell count score; study of frequencies 


\section{INTRODUÇÃO}

A contagem bacteriana total (CBT) do leite cru é um teste utilizado para avaliar a qualidade microbiológica do leite, indicando as condições de higiene na obtenção e no manuseio do leite nas propriedades. Altos valores indicam falhas na higiene dos equipamentos de ordenha, resfriamento, tempo e temperatura de armazenagem do leite, resultando em um produto com menor rendimento para queijo, diminuição do tempo de prateleira e falta de estabilidade dos produtos, prejudicando 0 processamento de derivados (Hill et al., 2011). Interferindo na percepção de qualidade do leite e seus derivados pelo consumidor, de importância econômica para a cadeia agroindustrial (Santos e Fonseca, 2006).

A contagem de células somáticas (CCS) do leite é um método de diagnóstico da mastite subclínica, consagrada internacionalmente como a medida padrão para determinar a qualidade do leite cru (Harmon, 1998b; Philpot, 1998b e Smith, 1998). Diversos autores, tal como Monardes (1998) e Wells e Ott (1998), relatam que altas CCS influenciam a composição do leite, afetando sua qualidade, alterando a permeabilidade dos vasos sanguíneos da glândula mamária e reduzindo a secreção dos componentes do leite pela ação direta dos patógenos ou de enzimas.

Programas de gerenciamento de rebanhos leiteiros têm utilizado o escore da contagem de células somáticas (ECS), auxiliando na avaliação da qualidade do leite, permitindo mensurar a prevalência da mastite no rebanho. ECS é resultado da transformação logarítmica da CCS, segundo Ali \& Shook, (1980).

As relações entre a CBT, $\log C B T$ e a CCS e ou ECS, foram estudadas anteriormente por diversos autores, entre eles Suhren \& Walte (2000),
Schaik et al., (2005), Colla (2009), Alberton et al., (2012) e Bozo et al., (2013), justificando as variações encontradas pela associação linear entre as variáveis. Pois, CCS maiores que um milhão de células $/ \mathrm{mL}$, estão correlacionadas positivamente com 0 aumento da CBT do leite, refletindo deficiências nas boas práticas de ordenha e higiene dos equipamentos de ordenha.

Segundo Mezzadri (2014), do Departamento de Economia Rural (DERAL) da Secretaria de Estado da Agricultura e Abastecimento (SEAB), o Estado do Paraná coloca-se como o $3^{\circ}$ maior produtor nacional de leite, com uma produção de 3,96 bilhões de litros, participando com $12 \%$ da produção brasileira, que em 2012, registrou 32,3 bilhões de litros. Todavia, segundo Koehler (2000), a caracterização racial do rebanho leiteiro paranaense apresenta: $28,4 \%$ de animais da raça Holandesa, 5,7\% Jersey, 17,7\% Girolanda, 8,0\% Pardo-Suíça e 40,2\% não possuem raça definida.

Para o monitoramento mensal da qualidade do leite as indústrias de laticínios do Paraná em atendimento ao Programa Nacional de Melhoria da Qualidade do Leite - PNMQL, consolidado pelas Instruções Normativas №51 e 62 (BRASIL, 2002 e 2011) do Ministério da Agricultura, Pecuária e Abastecimento (MAPA) se utilizam dos serviços do Laboratório de Análise da Qualidade do Leite (LQL) do Programa de Análise de Rebanhos Leiteiros do Paraná (PARLPR) da Associação Paranaense de Criadores de Bovinos da Raça Holandesa (APCBRH), credenciado pelo MAPA e participante da Rede Brasileira da Qualidade do Leite (RBQL).

Em 2011 o MAPA alterou a IN 51 Brasil (2002), publicando em Diário Oficial da União de 30/12/2011 instrução normativa, IN 62 Brasil (2011), contendo novas normas de produção e qualidade 
do leite, para vigorar a partir de 01/01/2012 estabelecendo novos parâmetros para componentes do leite, CBT e CCS.

Assim, o objetivo desta pesquisa foi avaliar a influência do ECS na CBT e logCBT, em amostras refrigeradas de leite de tanque individuais, comunitários e latões coletadas pelas indústrias de laticínios em dez regiões do Paraná.

\section{MATERIAL E MÉTODOS}

Para o estudo da CBT e logCBT, foram utilizadas 685.032 amostras refrigeradas de leite de tanques individuais, comunitários e latões coletadas pelas indústrias de laticínios em propriedades localizadas em 10 regiões no Estado do Paraná, analisadas no período de janeiro de 2012 a maio de 2014.

As amostras de leite de tanques foram coletadas mensalmente nas propriedades por pessoal treinado pelas indústrias de laticínios, segundo os procedimentos recomendados pelos manuais de Operações de Campo (Horst, 2008) e de Coleta de Amostras (Horst, 2010) do LQL do PARLPR da APCBRH, Curitiba-PR. As amostras foram coletadas em frascos esterilizados $(70 \mathrm{~mL})$, utilizando-se 0 bacteriostático azidiol, para a CBT. Porém, para CCS as amostras foram coletadas em frascos, utilizando-se do conservante bronopol e enviadas ao LQL em caixa isotérmica com gelo para manter a temperatura abaixo de $7^{\circ} \mathrm{C}$. $\mathrm{O}$ número de dias decorridos entre a coleta de leite na fazenda e sua análise no LQL em Curitiba-PR, foi definido como sendo a idade da amostra.

A análise das características estudadas foi realizada utilizando-se do seguinte modelo estatístico:

$$
Y_{i j k l m}=\mu+M_{i}+A_{j}+R_{k}+E C S_{l}+I_{m}+e_{i j k l m}
$$

Em que:
Yijklm = observação referente à CBT e ao logCBT de amostras de leite de tanques, coletadas no mês i, no ano $j$, na região $k$, ECSm, com idade da amostra I e erro aleatório associado a cada observação eijklm, onde:

$\mu \quad=$ média geral;

$\mathrm{Mi} \quad=$ efeito do mês de análise i, sendo i = 1 (jan), 2 (fev), ..., 12 (dez);

$\mathrm{Aj}=$ efeito do ano de análise j, sendo j = 2012, 2013 e 2014*;

$\mathrm{Rk}=$ efeito da região de análise $k$, sendo $k=1,2, \ldots, 10$;

$\mathrm{ECSI}=$ escore da contagem de células somáticas, sendo $m=0,1, \ldots 9$;

$\mathrm{Im} \quad=$ efeito da idade da amostra em dias $\mathrm{I}$, sendo $\mathrm{I}=0,1, \ldots, 7$;

eijklm = erro aleatório associado a cada observação Yijklm.

*o ano de 2014 está representado apenas por amostras de leite coletadas nos cinco primeiros meses do ano.

A CBT é expressa em unidades formadoras de colônia por mililitros de leite $(\mathrm{UFC} / \mathrm{mL})$, realizada por citometria de fluxo no equipamento Bactocount $150 \AA$ IBC $\circledast$, cuja capacidade é de até 150 amostras/hora Bentley Instruments (2002). Todavia a variável CCS é o resultado da leitura do equipamento por citometria de fluxo, Somacount $300 \AA$ Bentley Instruments (1995), em mil células $/ \mathrm{mL}$. A CBT foi transformada em logarítmico, adotando-se a seguinte expressão: $\log 10$ UFC x mL-1.

O escore da contagem de células somáticas (ECS) é o resultado da transformação logarítmica da CCS, segundo Ali \& Shook, (1980), Shook (1982), obtida pela equação ECS = $\log 2(\mathrm{CCS} / 100)+3$.

Os valores de ECS correspondentes ao intervalo de CCS de zero a 12.000 células $/ \mathrm{mL}$ foram forçados a serem iguais a zero, para se evitarem números negativos.

A transformação logarítmica da CBT (x1.000 UFC/mL) para logCBT (log10 UFC $x \mathrm{~mL}-1)$, segundo Lopes 
Júnior et al. (2012); Alberton et al., (2012) e Takahashi, (2012), mostra maior precisão nas análises estatísticas, maior coeficiente de determinação, menor coeficiente de variação, menores erros-padrão e maior coeficiente de correlação.

A análise dos dados foi realizada adotando-se o programa computacional SAS® versão 9.3 (2011) pelo modelo estatístico tipo III, utilizando-se dos seguintes procedimentos Proc Means, Proc Freq, Proc GLM e Proc Corr. A comparação entre médias foi realizada por meio do Teste de Tukey a $1 \%$ de probabilidade.

\section{RESULTADOS E DISCUSSÃO}

As médias observadas, os respectivos desvios padrão e os coeficientes de variação foram: CBT $(1.307 \pm 1.859$ (x1.000 UFC/mL), 136,7\%); logCBT $(5,89 \pm 1,93(\log 10$ UFC $x \quad m L-1)$, 29,5\%); CCS (568 \pm 575 (x1.000 células $/ \mathrm{mL}) 96,10 \%)$; ECS (4,95 $\pm 1,36$, $30,06 \%)$ e idade da amostra (2,95 \pm 1,48 dias) de leite de tanques individuais, comunitários e latões analisados no período de 2012 a 2014, que encontram-se na tabela 1.

A Análise de Variância, mostrou efeito significativo $(P<0,01)$ do ECS sobre as variáveis $C B T$ e logCBT.

\begin{tabular}{|c|c|c|c|c|c|}
\hline Características & $\mathrm{N}$ & Média & \pm & DP & $\mathrm{CV}(\%)$ \\
\hline $\mathrm{CBT}^{1}$ & 680102 & 1.307 & \pm & 1.859 & 136,7 \\
\hline $\log \mathrm{CBT}^{2}$ & 680102 & 5,89 & \pm & 1,93 & 29,5 \\
\hline $\operatorname{ccs}^{3}$ & 680102 & 568 & \pm & 575 & 96,1 \\
\hline $\mathrm{ECS}^{4}$ & 680102 & 4,95 & \pm & 1,36 & 30,06 \\
\hline Idade da amostra (dias) & 680102 & 2,95 & \pm & 1,48 & - \\
\hline \multicolumn{6}{|l|}{$1(x 1.000$ UFC/mL) } \\
\hline \multicolumn{6}{|l|}{${ }^{2}\left(\log _{10}\right.$ UFC $\left.\times \mathrm{mL}^{-1}\right)$} \\
\hline \multicolumn{6}{|l|}{${ }^{3}(x 1.000$ células $/ \mathrm{mL})$} \\
\hline${ }^{4}\left(\log _{2}(\operatorname{CCS} / 100)+3\right)$ & & & & & \\
\hline
\end{tabular}

As médias encontradas nesta pesquisa, superam os limites legais exigidos pela IN 62 do MAPA (BRASIL, 2011) que estabeleceu novos valores para a CBT (média geométrica dos resultados de três meses em UFC/mL) de amostras de tanque de acordo com as regiões do Brasil e datas de vigor. Assim, para as regiões Sul, Sudeste e Centro-Oeste os limites estabelecidos foram de 600.000 $\mathrm{UFC} / \mathrm{mL}$ para CBT e de 500.000 células/mL para CCS até junho de 2014. Em países que consolidaram seus programas de melhoria da qualidade do leite como Canadá, EUA e da União Europeia, as unidades formadoras de colônias são muito inferiores (28.000 a $37.753 \mathrm{UFC} / \mathrm{mL}$ ), em relação às encontradas nesta pesquisa.

Segundo Hillerton e Berry (2004), os EUA e a União Europeia adotaram o limite legal de $100.000 \mathrm{UFC} / \mathrm{ml}$. No Reino Unido, em 2003 as médias mensais no verão foram de 28.000 a $35.000 \mathrm{UFC} / \mathrm{mL}$. Bem como, a Federação dos Produtores de Leite do Quebec-Canadá (FPLQ 2011, 2012), publicou em 2011 e 2012 os valores médios de 37.753 e $38.727 \mathrm{UFC} / \mathrm{mL}$, respectivamente.

$\mathrm{O}$ estudo de frequências das amostras da CBT, segundo as classes estabelecidas encontram-se na figura 1. Nesta, observa-se que $48,72 \%$ das amostras se enquadram nas classes entre seis e nove (501 a $9.000 \times 1.000$ $\mathrm{UFC} / \mathrm{mL}$ ). Estas, estão muito acima daquelas estabelecidas pelos serviços de controle de rebanhos leiteiros dos Estados Unidos, Canadá e Países da União Europeia, que tem como meta atingir no máximo classe dois (26 a 50 $\mathrm{x} 1.000 \mathrm{UFC} / \mathrm{mL}$ ), ou seja, que os rebanhos apresentem até $50 \mathrm{mil}$ $\mathrm{UFC} / \mathrm{mL}$ no leite crú, pois, segundo Silva (2014), valores acima já são considerados elevados, merecendo atenção dos produtores. 


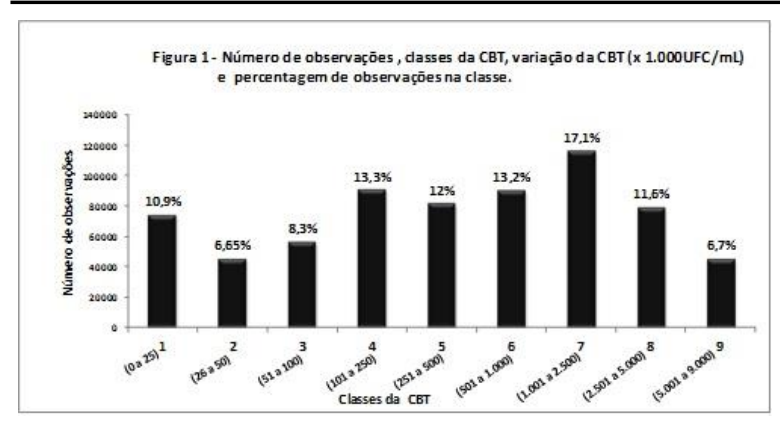

O estudo de frequências das amostras da CCS, transformadas em ECS, encontram-se na figura 2. Segundo as classes estabelecidas, observa-se que $64,95 \%$ das amostras se enquadram no escore cinco ou menos. Estes resultados estão abaixo dos objetivos estabelecidos pelos serviços de controle de rebanhos leiteiros dos Estados Unidos e Canadá, que tem como meta atingir um nível tal que $80 \%$ de seus rebanhos apresentem, no máximo, escore três (Monardes, 1998).

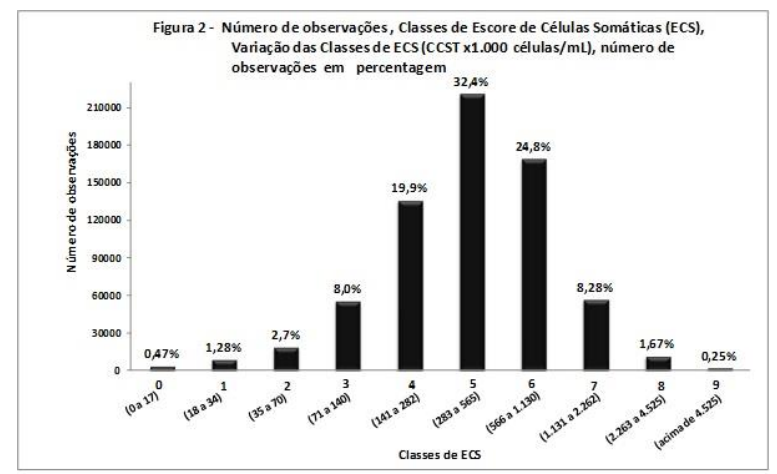

Segundo as classes estabelecidas de ECS, observa-se que $35,0 \%$ das amostras se enquadram no escore seis ou mais (566 a maior que $4.525 \times 1.000$ células $/ \mathrm{mL}$ ) refletindo um elevado nível de mastite nos rebanhos analisados, justificando portanto a necessidade da implementação de políticas públicas como programas que foquem a saúde da glândula mamária, pagamento do leite por qualidade pelas indústrias de laticínios com foco na CCS e CBT e a implementação dos limites legais estabelecidos pela IN 62 (BRASIL,
2011) do MAPA, visando a redução dos valores da CCST e de perdas na produção. Pois, segundo Harmon e Reneau (1993), o ECS cinco ou mais, estaria associado com $16 \%$ de quartos infectados e $6 \%$ de perdas na produção de leite nos rebanhos estudados.

$O$ efeito de ECS influenciou significativamente as variáveis CBT e logCBT $(P<0,01)$. As médias ajustadas, os respectivos erros padrão para CBT e logCBT segundo as classes de ECS, encontram-se na tabela 2. Nesta, observamos que quando o ECS variou de zero para nove (de zero para acima 4.525.000 células $/ \mathrm{mL}$ ) a CBT aumentou de 461 para $3.451(x 1.000 U F C / m L)$ e 0 logCBT de 4,05 para 7,46 (log10 UFC $x$ $\mathrm{mL}-1)$. Ficando evidente, uma associação linear entre as variáveis, ou seja, conforme aumenta a quantidade de CCS no leite, aumentam os valores da CBT e do logCBT.

Diferenças significativas entre a CBT, logCBT e o ECS, também foram relatadas anteriormente por diversos autores, entre eles Suhren \& Walte (2000), Schaik et al., (2005), Colla (2009), Alberton et al., (2012) e Bozo et al., (2013), que justificaram as variações pela associação linear entre as variáveis. Pois, CCS maiores que um milhão de células $/ \mathrm{mL}$, estão correlacionadas positivamente com 0 aumento da CBT do leite, refletindo deficiências nas boas práticas de ordenha e na higiene dos equipamentos de ordenha.

Todavia, conflitando com tais resultados, Lima et al., (2006), não encontraram variação bacteriana significativa em diferentes intervalos de CCS, destacando não haver necessariamente relação entre CCS e CBT no leite. 
ALI, A. K. A.; SHOOK, G. E. Na optimum transformation for matic cell concentration in milk. Journal of Dairy Science, Champaign, v. 63, p. 487-490, 1980.

BENTLEY INSTRUMENTS. Somacount 300 operator's manual. Chaska - EUA, Bentley Instruments INC, p12, 1995b.

BENTLEY INSTRUMENTS INC. BactoCount 150 operator's manual. Chaska -EUA, Bentley Instruments INC., p.49, 2002.

BOZO, G.A.; ALEGRO, L.C.A.; SILVA, L.C.; et al.; Adequação da contagem de células somáticas e da contagem bacteriana total em leite cru refrigerado aos parâmetros da legislação. Arquivo Brasileiro de Medicina Veterinária e Zootecnia, Belo Horizonte, v.65, n.2, p.589-594, 2013.

BRASIL. Portaria nำ1, do Ministério da Agricultura e do Abastecimento, de 18 de setembro de 2002. Aprova os regulamentos técnicos de produção, identidade e quantidade do leite tipo $A$, do leite tipo $B$, do leite tipo $C$, do leite pasteurizado e do leite cru refrigerado e o regulamento técnico da coleta de leite cru refrigerado e seu transporte a granel, em conformidade com os anexos a esta Instrução Normativa. Diário Oficial da Republica do Brasil, Brasília, n.321, 20 set., 2002.

BRASIL. Ministério da Agricultura, Pecuária e do Abastecimento. Altera a Instrução Normativa no51/2002. Estabelece novos prazos e limites para a redução de CBT e CCS até o ano de 2016, chegando aos valores de $100 \mathrm{mil} / \mathrm{ml}$ e 400 $\mathrm{mil} / \mathrm{ml}$, respectivamente. Suprime os Regulamentos Técnicos de Identidade e Qualidade dos leites tipos "B" e "C". Portaria $\mathrm{n}^{\circ}$ 62, de 30 de dezembro de 2011. Diário Oficial da República Federativa do Brasil, Brasília, DF, no. 251,30 dez. 2011.

COLLA, M.F. Valor da haptoglobina no plasma comparado com a contagem de células somáticas do leite no diagnóstico da mastite subclínica em vacas leiteiras. 2009. Rio Grande do Sul, 67f. Dissertação (Mestrado em Ciências Veterinárias) - Universidade Federal do Rio Grande do Sul.
FPLQ. Le lait, source durable de développement. Fédération des Producteurs de Lait du Québec, Rapport annuel 2011, p. 26, $2011 . \quad$ Disponível em: $<$ http://www.lait.org/fichiers/RapportAnnuel/FPL Q-2011/RapportAnnuel2011.pdf>. Acesso em: 07/03/2015.

FPLQ. Le Cycle De Vie Du Lait. Fédération des Producteurs de Lait du Québec, Rapport annuel 2012, p. 23, 2012. Disponível em: <http://www.lait.org/fichiers/RapportAnnuel/FPL Q-2012/RapportAnnuel2012.pdf>. Acesso em: 14/05/2015.

HARMON, R. J.; RENEAU, J. K. Factors affecting somatic cell counts in milk. In: NATIONAL MASTITIS COUNCIL ANNUAL MEETING, 32., 1993, Arlington. Proceedings... Madison: National Mastitis Council, 1993, p. 4857.

HARMON, R. J. Aspectos econômicos da mastite bovina. In: SIMPÓSIO INTERNACIONAL SOBRE QUALIDADE SO LEITE, 1., 1998, Curitiba. Anais...Curitiba, 1998ª, p.36-39.

HILL, J. A. G.; SILVEIRA, A. L. F. da; MIGLIORINI, F.; et al.; Qualidade do leite na região sudoeste do Paraná. Londrina: IAPAR, 2011. 56 p. (IAPAR, Boletim técnico, 76).

HILLERTON, J.E. E BERRY, E.A. Quality of the milk supply: european regulations versus practice. NMC Annual Meeting Proceedings, 2004, p.207-214.

HORST, J.A. Manual de Operações de Campo. Curitiba: Programa de Análise de Rebanhos Leiteiros do Paraná - APCBRH, p.16, 2008.

HORST, J.A. Manual de Coleta de Amostras: Componentes e CCS. Curitiba: Programa de Análise de Rebanhos Leiteiros do Paraná APCBRH, 2010.

KOEHLER, J. C. Caracterização da bovinocultura de leite no Estado do Paraná. Curitiba: DERAL/SEAB, 2000. Disponível em: <http://www.pr.gov.br/seab/deral/cultura3.pdf>. Acesso em: 27/05/2015 
LIMA, M.C.G.; SENA, M.J.; MOTA, R.A.; et al.; Contagem de células somáticas e análises físico-químicas e microbiológicas do leite cru tipo C produzido na região agreste do estado de Pernambuco. Arquivo do Instituto Biológico, v.73, n.1, p.89-95, 2006.

LOPES JÚNIOR, J. E. F.; LANGE, C. C.; BRITO, M. A. V. P. e; et al.; Relationship between total bacteria counts and somatic cell counts from mammary quarters infected by mastitis pathogens. Ciência Rural, Santa Maria, v.42, n.4, p.691-696, 2012.

MEZZADRI, F. P. Análise da Conjuntura Agropecuária Ano 2013/14 - Leite DERAL/SEAB 2014. Disponível em: $<$ http://www.agricultura.pr.gov.br/arquivos/File/d eral/Prognosticos/leite_2013_14.pdf>Acesso em 26/05/2015.

MONARDES, H. Programa de pagamento de leite por qualidade em Québec, Canadá. In: SIMPÓSIO INTERNACIONAL SOBRE QUALIDADE DO LEITE, 1., 1998, Curitiba. Anais... Curitiba, 1998. p. 40-43.

PHILPOT, W. N. Importância da contagem de células somáticas e outros fatores que afetam a qualidade do leite. In: SIMPÓSIO INTERNACIONAL SOBRE QUALIDADE DO LEITE, 1., 1998, Curitiba. Anais... Curitiba, 1998b, p. 28-35.

SANTOS, M.V.; FONSECA, L.F.L. 2006. Estratégias para Controle de Mastite e Melhoria da Qualidade do Leite. 1.ed. Barueri: Editora Manole, p.314.

SAS® System for Linear Models, version 9.3. Cary: SAS institute, 2011.

SCHAIK, G.V.; GREEN, L.E.; GUZMÁN, D.; et al. Risk factors for bulk milk somatic cell counts and total bacterial counts in smallholder dairy farms in the 10th region of Chile. Preventive Veterinary Medicine Journal, v.67, n.1, p.1-17, 2005.
SHOOK, G.E. Aproaches to summarizing somatic cell count which improve interpretability. In: NATIONAL MASTITIS COUNCIL ANNUAL MEETING, 21, 1982, Pennsylvania. Proceedings... Madison: National Mastitis Council, 1982, p.150-166.

SILVA, A.C.L. da.; Como produzir leite com baixa contagem bacteriana. Cartilha leite de qualidade, Clínica do Leite-ESALQ-USP, edição. v.8, p.4, 2014

SMITH, K. L.; HOGAN, J. S. Milk quality: a worldwide perspective. In: NATIONAL MASTITIS COUNCIL ANNUAL MEETING, 37., 1998, St. Louis. Proceedings... Madison: National Mastitis Council, 1998. p. 3-9.

SUHREN, G.; WALTE, H.G. First experiences with automatic flow cytometric determination of total bacterial count in raw milk. Bulletin of the international Dairy Federation (IDF), n.358, p.3648, 2000.

TAKAHASHI, F. $H$. et al. Variação e monitoramento da qualidade do leite através do controle estatístico de processos. Ciência Animal Brasileira, Goiânia, v.13, n.1, p.99-107, 2012.

WELLS, S. J.; OTT, S. L. What is the current milk quality in the US? In: NATIONAL MASTITIS COUNCIL ANNUAL MEETING, 37., 1998, St. Louis. Proceedings... Madison: National Mastitis Council, 1998. p. 10-18. 